\title{
INDÚSTRIA 4.0 \\ REPERCUSSÕES DA QUARTA REVOLUÇÃO \\ INDUSTRIAL E NOTAS SOBRE A MANUFATURA \\ AVANÇADA NO BRASIL
}

Alexandre da Silva de Oliveira ${ }^{1}$

\section{RESUMO}

$\mathrm{O}$ artigo estuda a indústria 4.0 e os desdobramentos na competitividade da economia brasileira. Está em desenvolvimento uma indústria automatizada, na qual há uma integração entre tecnologias físicas e digitais, meios de fabricação e os produtos permitindo uma troca de informações, com difusão de telecomunicações e tecnologias da informação. A partir de dados empíricos e da pesquisa bibliográfica, pode-se observar que há dependências de gastos em pesquisa e desenvolvimento, ambiente de negócios favorável para a manufatura avançada e interdependências entre esta e a infraestrutura logística. No Brasil, constatou-se que é preciso se combinar fatores macroeconômicos, política industrial e de comércio exterior para o país atingir uma indústria moderna e competitiva em escala internacional.

Palavras-chave: Indústria 4.0; Indústria manufatureira; Brasil.

1 Economista e Mestre em Economia, com formação pela Columbia University (EUA) e pela PUC/SP. Professor de Economia da Fundação Instituto de Administração, Universidade Paulista e Faculdades Integradas Campos Salles. Coordenador do curso de Ciências Econômicas da Universidade Paulista. Pesquisador do Grupo de Desenvolvimento Econômico e Política Econômica (DEPE), do Programa de Estudos Pós-graduados em Economia Política da PUC/SP. 
-• Economia Brasileira em Debate

\section{ABSTRACT}

The paper aims the industry 4.0 and the spillovers in the Brazilian competitiveness. Modernized industry is developing, in which there is integration between physical and digital technologies, means of manufacture and the products allowing an exchange of information, with diffusion of telecommunications and information technologies. From empirical data and from the bibliographic research, it can be observed that there are dependencies on research and development expenditures, favorable business environment for advanced manufacturing and interdependencies between this and the logistics infrastructure. In Brazil, it is necessary to combine macroeconomic factors, industrial policy and foreign trade for the country to achieve a modern and competitive industry on an international scale.

Keywords: Industry 4.0; Manufactured industry; Brazil.

\section{INTRODUÇÃO}

Uma fábrica ou planta industrial inteligente, na qual toda a cadeia produtiva se desenvolve em linha com o que foi planejado, com processos em funcionamento eficiente, integração de tecnologias físicas e digitais e com produção com alto rendimento há muito tempo faz parte do imaginário de gestores industriais e economistas. Este paradigma produtivo, que foi alçado a uma verdadeira revolução, foi mais bem engendrado por acadêmicos e industriais advindos da Alemanha, especialmente a partir de 2012, com a nomenclatura de Indústria 4.0 ou manufatura avançada, conforme as palavras de Sugayama e Negreli (2016):

Indústria 4.0 é um acrônimo que foi utilizado pela primeira vez na Alemanha para designar a evolução da indústria atual para uma indústria automatizada, na qual os meios de fabricação e os produtos estão interconectados permitindo que, decorrentes da troca de informaçõos entre eles, decisões de produção sejam tomadas de maneira autônoma pelas ferramentas e sistemas da fábrica. Fábrica que passa a ostentar o status de “cyber-indústria”. (SUGAYAMA; NEGRELI, 2016, p. 2).

Para os mesmos autores, não haveria nenhum excesso na característica revolucionária desta nova etapa industrial. Desta feita, a indústria 4.0, que é caracterizada pela utilização "de sistemas industriais inteligentes, que poderão tomar decisões de fabricação autônomas, apoiados em estruturas complexas de tratamento e manipu- 
lação de dados. Dados estes que serão gerados pela interconexão dos meios de produção com seus produtos, bem como conexão com o ambiente interno e externo da indústria, incluindo o cliente final." (SUGAYAMA; NEGRELI, 2016, p. 3).

Isto posto, busca-se compreender o conceito da indústria 4.0 e os desdobramentos na competitividade da economia brasileira. O estudo da indústria 4.0 se justifica pelo fato de ser necessária a compreensão da contribuição brasileira na divisão internacional da indústria, a partir da segunda década do século XXI.

\section{A INDÚSTRIA 4.0 OU MANUFATURA AVANÇADA}

A indústria 4.0 (ou quarta revolução industrial) seria a sucessora das três revoluções anteriores, a saber: Primeira era: utilização de máquinas a vapor como propulsor da indústria (século XVIII). Segunda era: utilização da eletricidade (final do século XIX) e; Terceira era: Automação (a partir o século XX). No século XXI, em um contexto de globalização produtiva das empresas transnacionais, e o desenvolvimento das telecomunicações e tecnologias da informação, surgiram derivados como sensores, sistemas e softwares. Para Coelho (2016, p. 15), assim podem ser descritas as etapas das quatro revoluções industriais:

Figura 1 Revoluções industriais - etapas.

19 REVOLUÇÃo INDUSTRIAL

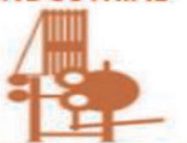

Máquinas a

Vapor

1784 2a REVOLUÇÃO INDUSTRIAL
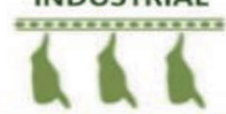

Produção em Massa Energia Elétrica 1870

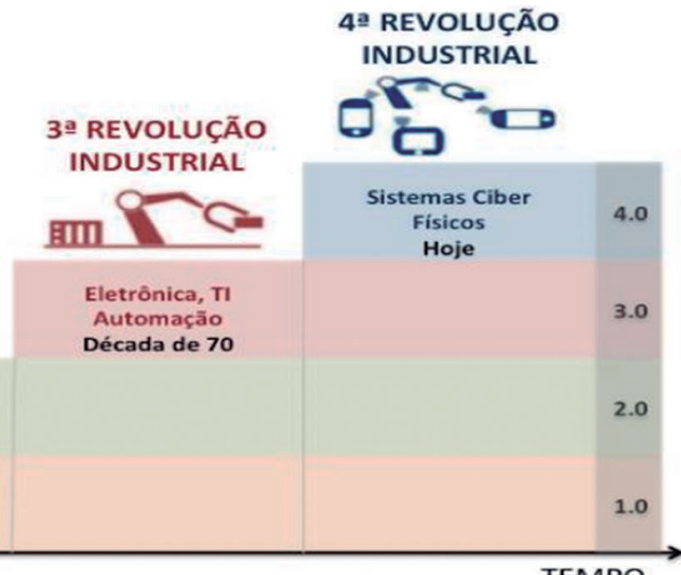

TEMPO

Fonte: Extraído de Coelho, 2016, p. 15.

A indústria 4.0 é classificada de acordo com a utilização nas etapas da cadeia produtiva, que inclui os processos, o desenvolvimento de processos, o desenvolvimento de produtos ou de novos modelos de negócios e projetos aplicados na indústria. Há uma classificação, por intensidade tecnológica da OCDE (anexo I) e uma 
classificação exemplificativa das aplicações da indústria 4.0, nas etapas da cadeia produtiva industrial é elencada na tabela a seguir:

Tabela 1 Etapas da cadeia produtiva e exemplos de tecnologias da indústria 4.0.

\begin{tabular}{|c|c|}
\hline Etapas da cadeia produtiva & Exemplos de tecnologias da Indústria 4.0 \\
\hline \multirow{4}{*}{ Processos } & Automação digital sem sensores. \\
\hline & Automação digital com sensores para controle de processo. \\
\hline & Monitoramento e controle remoto da produção com sistemas. \\
\hline & $\begin{array}{l}\text { Automação digital com sensores com identificação de pro- } \\
\text { dutos e condiçōes operacionais e linhas flexíveis. }\end{array}$ \\
\hline \multirow{3}{*}{ Desenvolvimento de processos } & $\begin{array}{l}\text { Sistemas integrados de engenharia para desenvolvimento } \\
\text { de produtos e manufatura de produtos. }\end{array}$ \\
\hline & $\begin{array}{l}\text { Manufatura aditiva, prototipagem rápida ou impressão } \\
\text { 3D. }\end{array}$ \\
\hline & $\begin{array}{l}\text { Simulações/análise de modelos virtuais (elementos finitos } \\
\text { e fluidodinâmicos computacionais). }\end{array}$ \\
\hline \multirow{3}{*}{$\begin{array}{l}\text { Desenvolvimento de produtos/ } \\
\text { novos modelos de negócios }\end{array}$} & $\begin{array}{l}\text { Coleta, processamento e análise de grandes quantidades de } \\
\text { dados (Big Data). }\end{array}$ \\
\hline & Utilização de serviços em nuvem associados ao produto. \\
\hline & $\begin{array}{l}\text { Incorporação de serviços digitais nos produtos (por exem- } \\
\text { plo, a "Internet das Coisas"). }\end{array}$ \\
\hline Projetos na indústria & Manufatura por computador. \\
\hline
\end{tabular}

Fonte: o autor.

Uma análise da relação entre a indústria e infraestrutura já fora empreendida por Oliveira (2015). Neste tocante, o autor destaca as externalidades e complementaridades que ocorrem entre os setores industriais, dentre eles a manufatura avançada e infraestrutura, o que inclui, por exemplo, o setor logístico:

Os investimentos em infraestrutura provocam transbordamentos, externos à firma, o que afeta as condições de acumulação de capital, por exemplo, na indústria de transformação. No que se refere à dinâmica de longo prazo do estoque de infraestrutura, a economia deve atingir um ciclo de crescimento, se houver um aumento do nível de infraestrutura como proporção do estoque de capital, o que induz um aumento do investimento do setor privado e um aumento do grau de utilização da capacidade produtiva devido à ampliação do consumo e à melhora das expectativas quanto à lucratividade na indústria de transformação. (OLIVEIRA, 2015, p. 624). 
Mais especificamente sobre a questão logística, um conceito subjacente foi desenvolvido quanto aos fatores infraestruturais ${ }^{2}$ incidentes sobre a indústria, que é o da Logística 4.0. Nas palavras de Fraga, Freitas e Souza (2016):

Atualmente, os esforços de pesquisa e desenvolvimento caminham para outros tipos de sistemas mais avançados, inteligentes e robotizados. (...) Os conceitos da Logística 4.0 podem ajudar os profissionais a reduzir a perda de ativos, gerar economia de custos de combustível, garantir estabilidade de temperatura, gerenciar estoque do armazém, ter uma visão do usuário e criar eficiência de frotas. Além de trazer um novo universo de possibilidades, a Internet das coisas também pode gerar benefícios que incrementam os processos da cadeia de abastecimento existentes, que abrangem a utilização de ativos, otimização de espaço de armazém ou planejamento da produção. (FRAGA; FREITAS; SOUZA, 2016, p. 113)

Quanto aos impactos da inovação tecnológica como, por exemplo, os advindos da automação industrial - característica marcante da indústria 4.0 -, não há, necessariamente, uma perda de ocupações ou empregos na indústria, mais está acaba por se reinventar, como destaca Kon (1994):

À medida que aumenta a automação, há a evolução de um nível para outro de qualificação, como por exemplo, pode haver a substituição do esforço manual pelo mecânico, ou a máquina passar para o controle com poder de "autocorreção" e de fornecer informaçōes que servem de base para decisões tais como seleção de velocidade, de temperatura etc. Dessa forma, as ocupações mais mecanizadas reduzem as funções do operador. No entanto, passa a existir a necessidade de outras tarefas indiretas como programação (informática), engenharia, matemática, que criam novos trabalhos especializados. (KON, 1994, p. 128).

A complexa relação entre indústria e serviços (que incluem os setores logísti$\cos )$, muitas vezes, são profundamente imbricadas, conforme palavras de Kon (2004):

Em certas indústrias manufatureiras, é difícil estabelecer a divisão entre a produção e os serviços. Por exemplo, a manufatura que utiliza equipamentos de processamento de dados, os insumos de serviços (software) são necessários para tornar operacional o processo produtivo [e logístico] e também têm uma grande influência sobre o sucesso do produto no mercado. (KON, 2004, p. 91). Destaques do autor.

2 De acordo com Velloso et al., "investir em infraestrutura de transportes [e logística] tem um impacto significativo na produtividade (...), porque aumenta o potencial de comércio externo do país, tanto via importação quanto da exportação." (VELLOSO et al., 2012, p. 129). 
Figura 2 Criação de valor na indústria e fatores impulsionadores - indústria 4.0: compasso digital.

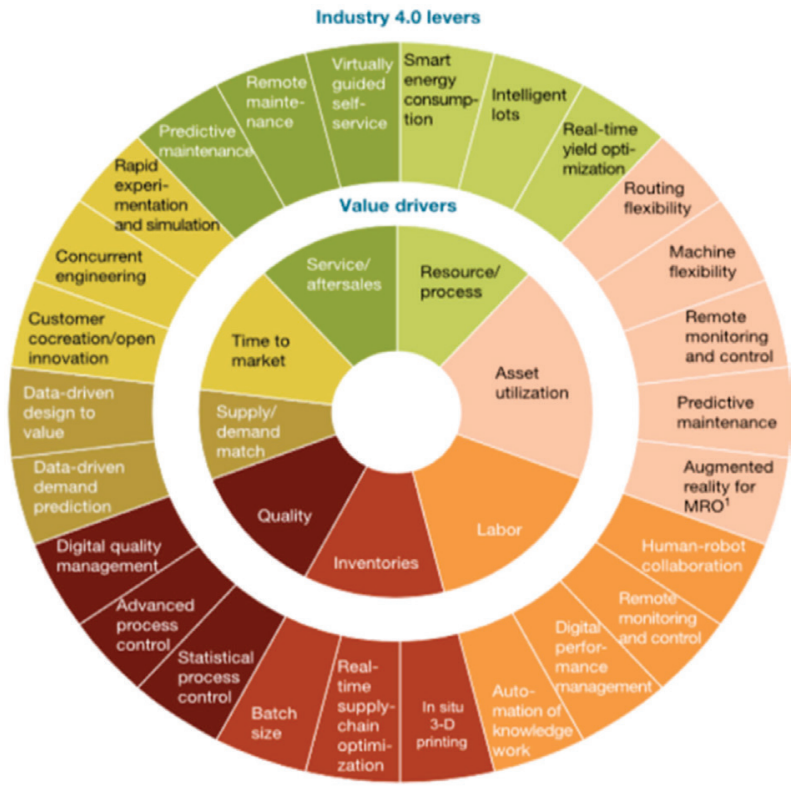

Fonte: extraído de CORNELIUS; DOMINIK - McKinsey, 2015, p. 2.

Por seu turno, de acordo com artigo intitulado "Manufacturing's next act", publicado em 2015 pela consultoria privada internacional Mckinsey, são identificadas oito áreas básicas da criação de valor (value drivers) na indústria e seus respectivos fatores impulsionadores (Industry 4.0 levers) pertencentes à indústria 4.0. O objetivo da figura - denominado de compasso digital -, é ajudar as organizações industriais a identificar as áreas de atuação de acordo com os problemas e desafios atuais, ao mesmo tempo em que oferece uma visão global do impacto esperado por esta transformação.

Dentre as áreas de criação de valor para as indústrias temos fatores como recursos e processos, utilização de ativos, serviços etc. Quanto aos fatores impulsionadores temos, por exemplo: controle de processos avançados, manutenção remota, consumo inteligente de energia, dentre outros (Figura 2).

A indústria 4.0 e os gastos empresariais em pesquisa e desenvolvimento (P\&D) tem relação direta ${ }^{3}$. De acordo com dados da consultoria privada internacional Strategy \&r, vinculada ao grupo $P w C$, os dez principais grupos econômicos mundiais

3 Ver em CHESNAIS (1996, p. 141-159). 
gastam em P\&D US\$12,1 bilhões - o que corresponde ao PIB de países como Bolívia, Costa Rica e El Salvador, somados. Os gastos em P\&D destas empresas, na média para os dez grupos, equivale a $13,1 \%$ de suas receitas brutas em escala global (anexo II).

\section{A INDÚSTRIA 4.0 NO BRASIL}

A partir da sondagem realizada pela Confederação Nacional da Indústria (CNI) com empresas industriais, podem-se extrair importantes informações sobre a dinâmica, especialmente das firmas presentes nos segmentos de manufatura avançada no Brasil. O estudo aponta que a adoção das tecnologias digitais é essencial para a competitividade das empresas, pois gera eficiência e produtividade no processo de produção.

No entanto, o baixo conhecimento é um entrave à utilização das tecnologias, pois $43 \%$ das firmas consultadas não identificaram quais tecnologias poderiam ser aplicadas para impulsionar a competitividade da indústria brasileira. Dentre as maiores companhias brasileiras que utilizam e desenvolvem tecnologias, temos a Petrobras, a Vale e a Embraer - sendo que a relação gastos em P\&D e receitas brutas atingiram, em média, apenas 1,8\% - ou seja, as empresas estrangeiras gastam em P\&D cerca de sete vezes mais que as empresas brasileiras (anexo II).

Uma questão a se destacar é o desconhecimento das empresas de pequeno porte, que atingiu $57 \%$ das firmas consultas no estudo. Em contrapartida, observou-se que os setores de alta e média-alta intensidade tecnológica utilizam mais tecnologias ligadas ao desenvolvimento como, por exemplo, em setores de equipamentos de informática, produtos eletrônicos e ópticos (61\%), máquinas, aparelhos e materiais elétricos (60\%) e máquinas e equipamentos $(53 \%)$ - embora utilizem as tecnologias de forma limitada, ou seja, focadas na melhoria de processos industriais.

Neste sentido, as firmas industriais no Brasil, com a aplicação das tecnologias advindas da Indústria 4.0 buscam benefícios como redução de custos operacionais, indicadas por $54 \%$ das corporaçóes e o aumento da produtividade, apontadas por 50 das empresas.

A implantação de uma Indústria 4.0 no Brasil está restrita, se observados outros fatores como uma percepção de alto custo de implantação, como uma das principais barreiras interna para as firmas $-66 \%$ das empresas apontaram esta 
debilidade. Outra limitação é a qualificação do trabalho, que é o principal desafio entre os fatores externos à firma, e apontada por 30\% das corporaçóes que participaram do estudo.

Quanto ao papel do governo, 46\% das empresas indicaram a necessidade de intensificação de esforços do poder público em educação e infraestrutura.

As tecnologias presentes na vanguarda industrial foram elencadas na Tabela 1 e se coadunam com a abordagem teórica de Joseph Schumpeter (1982), que analisou o processo de desenvolvimento da atividade produtiva, com os impactos advindos da tecnologia/inovação e o comércio exterior, como pode-se depreender o trecho a seguir:

Esse conceito [desenvolvimento] engloba os cinco casos seguintes: 1) introdução de um novo bem - ou seja, um bem com que os consumidores ainda não estiverem familiarizados - ou de uma nova qualidade de um bem. 2) introdução de um novo método que ainda não tenha sido testado pela experiência no ramo próprio da indústria de transformação, que de modo algum precisa ser baseada numa descoberta cientificamente nova, e pode consistir também em nova maneira de manejar comercialmente uma mercadoria. 3) abertura de um novo mercado, ou seja, de um mercado em que o ramo particular da indústria de transformação dos países em questão não tenha ainda entrado, quer esse mercado tenha existido antes ou não. 4) conquista de uma nova fonte de oferta de matérias-primas ou de bens semimanufaturados, mais uma vez independentemente do fato que essa fonte já existia ou teve que ser criada. 5) estabelecimento de uma nova organização de qualquer indústria, como a criação de uma posição de monopólio. (SCHUMPETER, 1982, p. 48). Destaque do autor.

Mais especificamente sobre o papel das políticas públicas na esfera econômica, no sentido de aumentar a dotação em termos de competitividade de uma economia, Kupfer e Hasenclever (2002) apontam:

Aspectos regulatórios, infraestruturais, sociais e mesmo macroeconômicos - sistêmicos, em suma - agem de forma decisiva para calibrar a intensidade do processo competitivo e eventualmente reforçar a competitividade das empresas ali atuantes e, por extensão, da indústria correspondente. Preservar e fortalecer a concorrência, nesse quadro, implica a criação/reprodução de um ambiente competitivo. Este compreende: (1) estratégias empresariais inovativas e a adoção de critérios de eficiência produtiva, no plano das empresas; e, (2) no plano do mercado, a presença sistemática de pressóes competitivas internas e potenciais (ameaça de entrada) e de fatores sistêmicos à concorrência e competitividade, seja oferecendo externalidades positivas (infraestrutura adequada, mão de obra qualificada etc.), seja assegurando condições macroeconômicas favoráveis ao crescimento e ao financiamento (KUPFER; HASENCLEVER, 2002, p. 428). 
Em termos de geração de valor adicionado, de acordo com dados do Banco Mundial, a preços correntes de 2014, o Brasil ocupou a nona colocação, em um ranking mundial, pelas suas dimensões continentais, que permitem que os grandes grupos empresariais multinacionais estejam localizados no país, com o propósito de atenderem ao grande contingente populacional, ainda está localizada entre as vinte maiores economias do mundo.

No entanto, cabe-nos uma análise comparativa da geração de valor adicionado na indústria manufatureira no Brasil, sendo que: na Alemanha é três vezes maior, no Japão é três vezes e meia maior e nos EUA é oito vezes maior. Em uma análise com os países concorrentes do Brasil, temos: Coreia do Sul é mais do que três vezes maior e Índia é $25 \%$ maior do que o valor adicionado no território brasileiro (Gráfico 1).

Gráfico 1 Mundo: valor adicionado pela indústria manufatureira (US\$ bilhões, preços correntes de 2014).

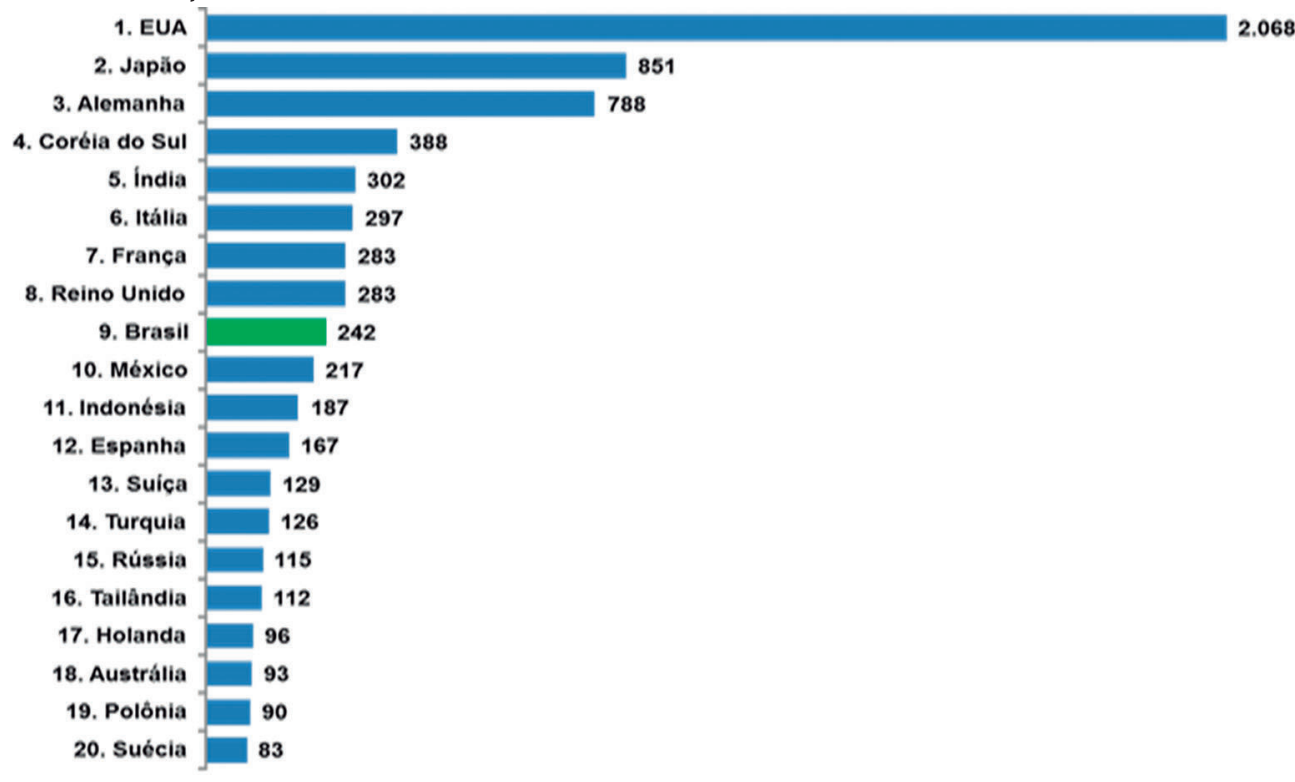

Fonte: Banco Mundial, elaborado pelo autor.

Adicionalmente, é preciso um destaque quanto à relação entre a política industrial e de comércio exterior. Esta se manifesta, precipuamente, com utilização de subsídios, com o objetivo de fomentar a indústria brasileira face aos concorrentes internacionais - desta forma, a atuação pública visa aumentar a competitividade da indústria - condição necessária que se justifica, de acordo com Caparroz (2016): 
Ao incentivar a atividade empresarial mediante instrumentos jurídicos capazes de criar um ambiente saudável para o desenvolvimento dos negócios, com a desoneração tributária da cadeia produtiva, normas trabalhistas racionais, indicadores macroeconômicos (principalmente inflação e juros) equilibrados, aliados a baixos índices de burocracia e corrupção, o Estado colabora, diretamente, para o desenvolvimento da competitividade de suas organizações privadas no comércio internacional (CAPARROZ, 2016, p. 63).

Gráfico 2 Brasil: exportações de bens de capital e bens de consumo não duráveis e taxa de câmbio efetiva real* $(2006=100)$.

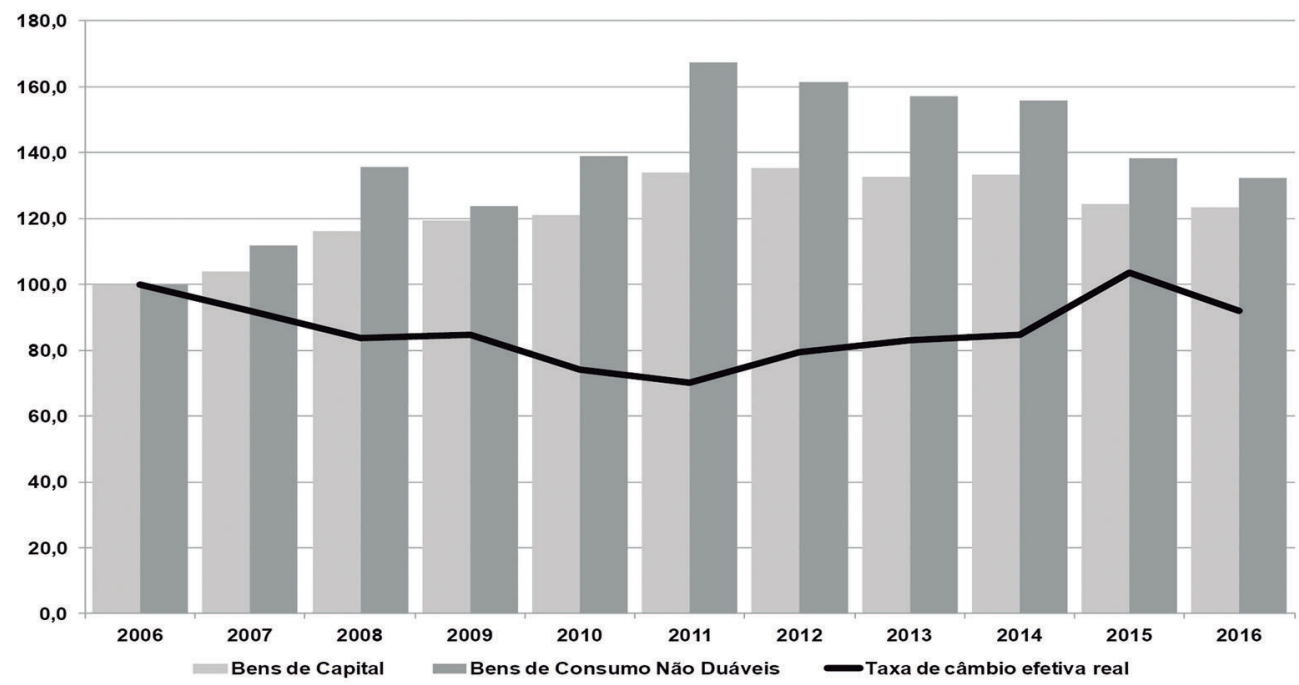

Fonte: Funcex e BCB, coletados no Ipeadata e elaborado pelo autor.

* Elaboração IPEA. Média aritmética ponderada das taxas de câmbio reais bilaterais do país em relação a 24 parceiros comerciais selecionados. A taxa de câmbio real bilateral é definida pelo quociente entre a taxa de câmbio nominal (em $\mathrm{R}$ \$ /unidade de moeda estrangeira) e a relação entre o Índice de Preços ao Produtor Amplo (IPA-EP-DI/FGV) do Brasil e o Índice de Preços ao Produtor (IPP) do país em caso. As ponderações utilizadas variam a cada ano, sendo obtidas pelas participações de cada parceiro no total das exportações brasileiras para os países considerados nos 2 anos imediatamente anteriores. A metodologia de cálculo foi atualizada e revisada em outubro de 2015, implicando o recálculo de toda a série histórica.

Além dos fatores elencados como prejudiciais, observados inclusive no Relatório de Competitividade Global (em inglês, The Global Competitiveness Report) ${ }^{4}$, do

4 Há também o Índice de Competitividade Mundial 2016 (World Competitiveness Yearbook WCY), divulgado pelo International Institute for Management Development, IMD, e pela Fundação Dom Cabral, que apontou a perda de espaço do Brasil no cenário competitivo internacional, com a queda de posiçóes pelo sexto ano consecutivo. O país ocupa agora a $57^{\mathbf{a}}$ colocação no ranking geral, descendo um degrau em relação a 2015. Neste ano, o Brasil está à frente apenas da Croácia, Ucrânia, Mongólia e Venezuela. O país soma um declínio de 19 posições em seis anos. 
Fórum Econômico Mundial, como elevado custo de financiamento, alta carga tributária e baixa abertura ao comércio exterior, pode-se observar no gráfico a seguir uma tendência de valorização da taxa de câmbio real efetiva - esta taxa que é um indicador da competitividade da produção brasileira se valorizou $8 \%$ no período 2006-2016 (Gráfico 2).

Nesse sentido, a partir de dados da Fundação Centro de Estudos do Comércio Exterior (Funcex), coletados no IPEDATA, é possível observar que a quantidade exportada (quantum) de bens de consumo não duráveis registrou uma taxa de crescimento anual de 3,0\%, enquanto as quantidades exportadas de bens de capital cresceram 2,0\% a.a. nos dez anos até o ano de 2016 - o que resulta em um crescimento acumulado de 32,0 e 23,0\%, respectivamente (Gráfico 2).

A partir dos dados apresentados nos gráficos anteriores, é necessária a coordenação efetiva de políticas públicas, quanto a fatores macroeconômicos, indústria e comércio exterior para a promoção e o estímulo de valor adicionado no país e melhorias na competitividade do país, em escala internacional.

\section{CONSIDERAÇÕES FINAIS}

O artigo buscou compreender o conceito da indústria 4.0 e os desdobramentos na competitividade da economia brasileira. É considerada uma quarta revolução industrial e significa uma indústria automatizada, na qual há uma integração entre tecnologias físicas e digitais, os meios de fabricação e os produtos permitindo que, decorrentes da troca de informações entre eles, decisões de produção sejam tomadas de maneira autônoma pelas ferramentas e sistemas da fábrica e é representada pelo desenvolvimento das telecomunicações e tecnologias da informação, bem como derivados como sensores, sistemas e softwares. A partir da pesquisa bibliográfica, pode-se observar que há dependências de gastos em pesquisa e desenvolvimento, ambiente de negócios propício para o desenvolvimento da manufatura avançada e interdependências entre esta e a infraestrutura de um país, em especial, a logística.

No Brasil, a partir dados empíricos e pesquisas bibliográficas, pode-se observar que há baixo conhecimento sobre a aplicação da tecnologia 4.0 e os potenciais ganhos, como também um elevado custo de implantação, representado pelo custo de financiamento no país, e debilidades sistêmicas como restrições de infraestrutura e baixos gastos em P\&D. É preciso se combinar fatores macroeconômicos, com políticas públicas como, política industrial e de comércio exterior para o país atingir uma indústria moderna e competitiva em escala internacional. 
-• Economia Brasileira em Debate

\section{REFERÊNCIAS}

CAPARROZ, R. (2016). Comércio internacional e legislação aduaneira esquematizado. 3. ed. São Paulo: Editora Saraiva.

CHESNAIS, F. (1996). A mundialização do capital. São Paulo: Xamã.

COELHO, P. (2016) Rumo à indústria 4.0. Dissertação apresentada para a obtenção do grau de Mestre em Engenharia e gestão Industrial. Departamento de Engenharia Mecânica. Universidade de Coimbra.

CORNELIUS, B.; DOMINIK, W. Manufacturing's next act, 06 2015. [Online]. Disponível: $<$ http://www.mckinsey.com/business-functions/operations/our-insights/manufacturingsnext-act>. Acessado em: 07.04.17.

CONFEDERAÇÃO NACIONAL DA INDÚSTRIA (CNI) Sondagem Especial: indústria 4.0. Disponível em: <http://www.portaldaindustria.com.br/relacoesdotrabalho/ media/publicacao/chamadas/SondEspecial_Industria4.0_abril2016.pdf>. Acessado em: 02.04.17.

FRAGA, M.; FREITAS, M.; SOUZA, G. (2016) Logística 4.0: conceitos e aplicabilidade - uma pesquisa-ação em uma empresa de tecnologia para o mercado automobilístico. FAE-NPA.

FUNDAÇÃO DOM CABRAL (FDC). Sumário executivo: Brasil precisa criar uma agenda positiva para reverter a trajetória de queda em ranking global de competitividade. Disponível em: <http://www.fdc.org.br/blogespacodialogo/Documents/2016/relatorio_ global_competitividade2016_sumario.pdf>. Acessado em: 20.04.17.

KON, A. (1994). Economia industrial. São Paulo: Editora Nobel.

(2004). Economia de serviços: teoria e evolução no Brasil. Rio de Janeiro: Elsevier.

KUPFER, D.; HASENCLEVER, L. (2002). Economia industrial: fundamentos teóricos e práticas no Brasil. Rio de Janeiro: Elsevier.

ORGANIZAÇÃO PARA A COORPERAÇÃO E DESENVOLVIMENTO ECONÔMICO (OCDE). Dados. Disponível em: <https://data.oecd.org/>. Acessado em: 23.04.17.

OLIVEIRA, A. (2015) Externalidades intersetoriais: uma análise das interconexões entre a infraestrutura e a indústria de transformação no Brasil nos anos 2000. Ensaios FEE, Porto Alegre, v. 36, n. 3, p. 621-642, dez.

SCHUMPETER, J. (1982) A teoria do desenvolvimento econômico. São Paulo: abril Cultural.

SUGAYAMA, R.; NEGRELLI, E. (2016) Veículo conectado na rota da indústria 4.0, p. 48-63. In: Anais do XXIV Simpósio Internacional de Engenharia Automotica - SIMEA 2016 [=Blucher Engineering Proceedings]. São Paulo: Blucher. 
STRATEGY \&. Ranking global dos investimentos em pesquisa e desenvolvimento. Disponível em: <https://fernandonogueiracosta.wordpress.com/2016/11/03/necessidade-de-projetobrasileiro-da-industria-do-futuro-padrao-4-0/>. Acessado em: 25.05.17.

WORLD BANK Dados. Disponível em: <http://data.worldbank.org/>. Acessado em: 25.04.17.

WORLD ECONOMIC FORUM. The Global Competitiveness Report. 2016-2017. Disponível em: <http://www3.weforum.org/docs/GCR20162017/05FullReport/TheGlobalCompetitivenessReport2016-2017_FINAL.pdf>. Acessado em: 21.04.17.

VELLOSO, R.; et al., (2012) Infraestrutura - os caminhos para sair do buraco: estudo mostra como o investimento em infraestrutura pode acelerar o crescimento econômico via produtividade e qualidade. Rio de Janeiro: Fórum Nacional - INAE.

\section{ANEXO I - CLASSIFICAÇÃO INDUSTRIAL POR INTENSIDADE TECNOLÓGICA}

\begin{tabular}{|c|c|}
\hline SETORES & CATEGORIAS \\
\hline \multicolumn{2}{|l|}{ Farmoquimicos e farmacéuticos } \\
\hline \multicolumn{2}{|l|}{ Equipamentos de informática, eletrônicos e ópticos } \\
\hline \multicolumn{2}{|l|}{ Quimicos (exceto HPPC) (1) } \\
\hline \multicolumn{2}{|l|}{ HPPC (1) } \\
\hline \multicolumn{2}{|l|}{ Máquinas, aparelhos e materiais elétricos } \\
\hline \multicolumn{2}{|l|}{ Máquinas e equipamentos } \\
\hline \multicolumn{2}{|l|}{ Veiculos automotores } \\
\hline \multicolumn{2}{|l|}{ Outros equipamentos de transporte } \\
\hline \multicolumn{2}{|l|}{ Coque, derivados do petróleo e biocombustiveis } \\
\hline \multicolumn{2}{|l|}{ Produtos de borracha } \\
\hline \multicolumn{2}{|l|}{ Produtos de material plástico } \\
\hline \multicolumn{2}{|l|}{ Minerais não metálicos } \\
\hline \multicolumn{2}{|l|}{ Metalurgia } \\
\hline \multicolumn{2}{|l|}{ Produtos de metal } \\
\hline \multicolumn{2}{|c|}{ Manutenção, reparação e instalação de máquinas e equipamentos } \\
\hline \multicolumn{2}{|l|}{ Alimentos } \\
\hline \multicolumn{2}{|l|}{ Bebidas } \\
\hline \multicolumn{2}{|l|}{ Fumo } \\
\hline \multicolumn{2}{|l|}{ Produtos têxteis } \\
\hline \multicolumn{2}{|l|}{ Vestuário e acessórios } \\
\hline \multicolumn{2}{|l|}{ Calçados e suas partes } \\
\hline \multicolumn{2}{|l|}{ Couros e artefatos de couro } \\
\hline \multicolumn{2}{|l|}{ Madeira } \\
\hline \multicolumn{2}{|l|}{ Celulose e papel } \\
\hline \multicolumn{2}{|l|}{ Impressão e reproduçāo } \\
\hline \multicolumn{2}{|l|}{ Móveis } \\
\hline Produtos diversos & \\
\hline
\end{tabular}


-• Economia Brasileira em Debate

\section{ANEXO II - RANKING GLOBAL}

Gastos em Pesquisa e Desenvolvimento (P\&D) - 2015 e 2016

\begin{tabular}{|l|c|c|cc|}
\hline Empresas & $\begin{array}{l}\text { Gastos em P\&D } \\
\text { (em US\$ bilhões) }\end{array}$ & $\begin{array}{l}\text { Gastos em } \\
\text { relação a receita }\end{array}$ & $\begin{array}{r}\text { Posição ranking } \\
\mathbf{2 0 1 5}\end{array}$ & $\mathbf{2 0 1 6}$ \\
\hline Volkswagen & 13,2 & $5,6 \%$ & $\mathbf{1}$ & $\mathbf{1}$ \\
\hline Samsung & 12,7 & $7,2 \%$ & $\mathbf{2}$ \\
\hline Amazon & 12,5 & $11,7 \%$ & $\mathbf{7}$ & $\mathbf{4}$ \\
\hline Alphabet (Google) & 12,3 & $16,4 \%$ & $\mathbf{4}$ & $\mathbf{6}$ \\
\hline Intel & 12,1 & $21,9 \%$ & $\mathbf{5}$ \\
\hline Microsoft & 12 & $12,9 \%$ & $\mathbf{9}$ & $\mathbf{8}$ \\
\hline Roche & 10 & $19,9 \%$ & $\mathbf{9}$ \\
\hline Novartis & 9,5 & $19,2 \%$ & $\mathbf{9}$ \\
\hline Johnson \& Johnson & 9 & $12,9 \%$ & $\mathbf{1 0}$
\end{tabular}

\begin{tabular}{|c|c|c|c|c|}
\hline \multirow{2}{*}{$\begin{array}{l}\text { Empresas } \\
\text { brasileiras }\end{array}$} & \multirow{2}{*}{$\begin{array}{l}\text { Gastos em P\&D } \\
\text { (em US\$ bilhões) }\end{array}$} & \multirow{2}{*}{$\begin{array}{l}\text { Gastos em } \\
\text { relação a receita }\end{array}$} & \multicolumn{2}{|c|}{ Posição ranking } \\
\hline & & & 2015 & 2016 \\
\hline Petrobras & 0,618 & $0,6 \%$ & 138 & 224 \\
\hline Vale & 0,489 & $1,9 \%$ & 184 & 265 \\
\hline Embraer & 0,188 & $3 \%$ & 642 & 562 \\
\hline
\end{tabular}

Fonte: Strateav\& 